\title{
An Empirical Analysis on Policy Effect of Inflation Targeting in Japan
}

\author{
Donghua Liu \\ Shanghai University of International Business and Economics \\ Shanghai, China
}

\begin{abstract}
Japan has been implementing the inflation targeting officially in the beginning of 2013. Only few associated studies have been reported yet. After conducting a survey of the background of implementing inflation targeting in Japan, this study employs the synthetic control method to analysis its policy effect. The results demonstrated that the policy effect of inflation targeting was not very satisfying, but it still inhibited the further deterioration of deflation to some extent.
\end{abstract}

Keywords-inflation targeting; the policy effect; Japan; the synthetic control method

\section{INTRODUCTION}

The second Abe Cabinet was founded on December, 2012. The primary goal of the Abe Cabinet is to help Japan out of the long-term dilemma in deflation and realize economic growth. Hence, the Abe Cabinet launched the pump priming policy composed of "bold monetary easing policy", "positive and flexible financial policy" and "economic growth strategies". Such policy combination is also called the "Abenomics".

In this background, the Bank of Japan (BOJ) made a great adjustment to the quantitative easing monetary policy on January, 2013. On January 22 ${ }^{\text {nd }}$, 2013, BOJ and the Japanese government released the Joint Statement, which determined the inflation target of $2 \%$ and announced to purchase assets infinitely since April to realize the target as soon as possible. This implies that Japan began to implement the monetary policy of inflation targeting officially.

This monetary policy has been implemented for 5 years. How does its policy effect? An empirical analysis on the inflation targeting was conducted in this paper.

\section{BACKGROUND OF IMPLEMENTING INFLATION TARGETING IN JAPAN}

Since its adoption of inflation targeting in March 1990, New Zealand has attracted many followers. Inflation targeting has been implemented by 30 countries around the world, and has been favored by a growing number of national central banks (TABLE I).

These countries adopted the inflation targeting for different motivations and in different backgrounds. In generally, these can be summarized as follows[4][7] [8]:

Firstly, originally exchange rate targeting could not be maintained upon the impact of monetary crisis (or financial

This research work was supported by Humanities and Social Science Foundation of China Ministry of Education ( No.16YJA790025). crisis) and it has to shift into the floating exchange rate system. Under this circumstance, the demand to seek the new "nominal anchor" of monetary policy forced them to make decisions of adopting inflation targeting.

TABLE I. INFLATION T ARGETERS

\begin{tabular}{|l|c|c||c|c|c|}
\hline Country & $\begin{array}{l}\text { adoption } \\
\text { date }\end{array}$ & $\begin{array}{l}\text { Inflation } \\
\text { rate at } \\
\text { adoption } \\
\text { date }\end{array}$ & Country & $\begin{array}{l}\text { Inflation } \\
\text { date } \\
\text { rate at } \\
\text { adoption } \\
\text { date }\end{array}$ \\
\hline $\begin{array}{l}\text { New } \\
\text { Zealand }\end{array}$ & 1990.03 & $3.3 \%$ & Peru & 1994.01 & $33.6 \%$ \\
\hline Canada & 1991.02 & $6.9 \%$ & Korea & 1998.04 & $6.2 \%$ \\
\hline UK & 1992.10 & $4.0 \%$ & Mexico & 1999.01 & $17.8 \%$ \\
\hline Sweden & 1993.01 & $1.8 \%$ & Thailand & 2000.05 & $0.8 \%$ \\
\hline Australia & 1993.04 & $2.0 \%$ & $\begin{array}{l}\text { South } \\
\text { Africa }\end{array}$ & 2000.02 & $2.6 \%$ \\
\hline Finland & 1993.02 & $2.6 \%$ & Hungary & 2001.06 & $10.8 \%$ \\
\hline Spain & 1994.11 & $4.2 \%$ & Philippin & 2002.01 & $4.5 \%$ \\
\hline Norway & 2001.03 & $3.6 \%$ & Guatemala & 2005.01 & $9.2 \%$ \\
\hline Iceland & 2001.03 & $4.1 \%$ & Slovakia & 2005.01 & $5.8 \%$ \\
\hline Chile & 1990.09 & $26.6 \%$ & Indonesia & 2005.07 & $7.4 \%$ \\
\hline Israel & 1992.01 & $16.9 \%$ & Romania & 2005.08 & $9.3 \%$ \\
\hline Czekh & 1998.01 & $6.8 \%$ & Turkey & 2006.01 & $7.7 \%$ \\
\hline Poland & 1998.10 & $10.6 \%$ & Serbia & 2006.09 & $10.8 \%$ \\
\hline Brazil & 1999.06 & $3.3 \%$ & Ghana & 2007.05 & $10.5 \%$ \\
\hline Colombia & 1999.09 & $9.3 \%$ & Japan & 2013.01 & $-0.6 \%$ \\
\hline & & $(S o u r c e: ~ H a m m o n d(2012)$ & $3]$, Roger(2009) & 66, Website of BOJ) \\
\hline
\end{tabular}

Secondly, these countries adopted inflation targeting to improve the domestic hyperinflation. Many countries that implemented the inflation targeting once had suffered serious inflation. For instance, emerging countries (e.g. Brazil and Chile) even experienced virulent inflation. Even some industrial countries were witnessing relatively high inflation level before the implementation of inflation targeting. As a result, these countries hope to inhibit hyperinflation and improve the "nature" of hyperinflation through inflation targeting.

\footnotetext{
1 Finland, the Slovak Republic, and Spain-adopted inflation targeting, but abandoned it when they began to use the euro as their currency.
} 
Thirdly, only one country (Japan) resorted to inflation targeting to get out of the long-term dilemma of deflation.

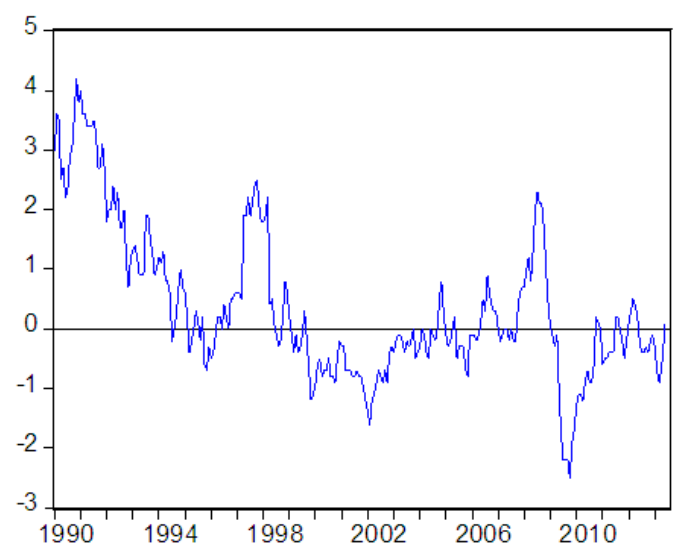

Fig. 1. CPI changes in Japan from 1990 to 2012 (\%)

(Source: this diagram was drawn by the author according to the data of Statistical Bureau of Japan)

As everyone knows, Japanese economy had been struggling with deflation for a long time since the bubble economic bust in early 1990s ( Fig.1). To address this problem, Krugman, a famous American economist, proposed this policy on May, 1998. He suggested that Japan shall adopt the inflation targeting and set a relatively high inflation target (i.e., $4 \%)$, aiming to "arouse" high inflation expectation and decrease the real interest rate and finally realizing the goal of stimulating economic recovery and getting rid of deflation.

This policy suggestion aroused fierce debate in Japan after it was proposed. Due to the objection of BOJ and frequent alternation of Cabinet of Japan, inflation targeting had not been implemented.

After the outburst of global financial crisis in 2008, Japanese economy was attacked significantly. Later, the Japanese economic environment further deteriorated by some domestic and foreign events, including the European Debt Crisis and Great East Japan Earthquake in 2011. The Japanese economy faced more serious depression and deflation pressure again. Under this circumstance, the appeal to inflation targeting was strengthened again.

On December, 2012, Shinzo Abe assumed the prime minister for the second time. Later, the Abe Cabinet launched the pump priming combination which was known as "Abenomics". The first term was to get rid of long-term deflation through a more positive quantitative easing monetary policy. In face of the great pressure from the Abe Cabinet, Shira-kawa, the president of BOJ, terminated his tenure in advance on January, 2013. Kuroda, a representative of advocating inflation targeting assumed the new president. In the same time, BOJ and the Japanese government released the Joint Statement, which symbolized the beginning of inflation targeting[5].

\section{EMPIRICAL ANALYSIS ON POLICY EFFECT}

\section{A. Price changes since 2013}

The price changes in Japan since the implementation of inflation targeting is shown in Fig.2. Obviously, the inflation target (2\%) was only realized in the fiscal year from 2014 to 2015, but it was failed in the subsequent 3 years. At this point, the performance of inflation targeting in Japan was not satisfying.

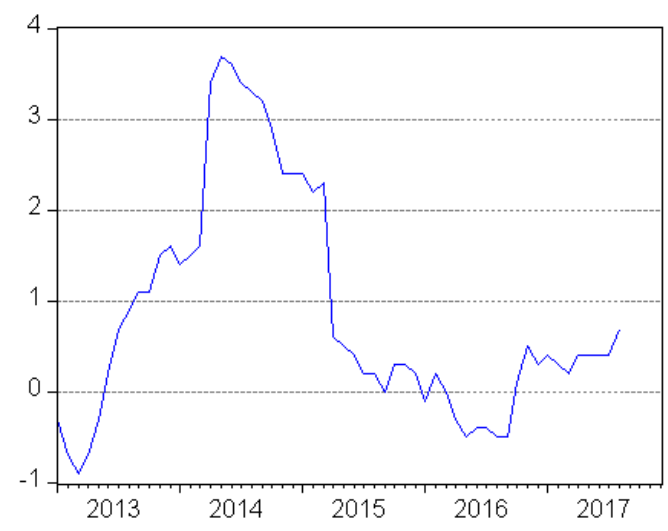

Fig. 2. CPI changes in Japan from early 2013 to August, 2017 (\%)

(Source: this diagram was drawn by the author according to the data of Statistical Bureau of Japan)

Although the performance of inflation targeting in Japan was not satisfying, whether it has some policy effect on inhibition of deflation still needs further deep studies.

\section{B. Introduction to the synthetic control method ${ }^{2}$}

Suppose that we observe units $k=1, \ldots, \mathrm{J}+1$ for time periods $\mathrm{t}=1, \ldots, \mathrm{T}$. Without loss of generality, we assume that only the first unit is exposed to the intervention so we have $K$ remaining control units that can contribute to the synthetic control. The set of control units is termed the donor pool. In the context of comparative case studies units are usually aggregate entities such as schools, regions, or countries, and the interventions or treatments are events such as economic shocks, the passages of laws, etc. The intervention occurs at time period $\mathrm{T}_{0}+1$, so that $1,2, \ldots, \mathrm{T}_{0}$ are the pre-intervention periods and $\mathrm{T}_{0}+1, \mathrm{~T}_{0}+2, \ldots, \mathrm{T}$ are the post-intervention periods.

We define two potential outcomes: $\pi_{i t}^{N}$ refers to the outcome that would be observed for unit $i$ at time $t$ if unit $i$ is not exposed to the intervention, and $\pi_{\mathrm{it}}^{I}$ refers to the outcome that would be observed if unit $i$ is exposed to the intervention. Our goal is to estimate the effect of the intervention on the outcome for the treated unit in the post-intervention period. This effect is formally defined as the difference between the two potential outcomes $\alpha_{i t}=\pi_{\mathrm{it}}^{I}-\pi_{i t}^{N}$. Notice that $\pi_{i t}^{N}$ is unobserved for the treated unit in the post-intervention period. The goal of the synthetic control method is to construct a

\footnotetext{
${ }^{2}$ A detailed discussion of the synthetic control estimator is provided in Abadie et al. (2010).
} 
synthetic control group that yields a reasonable estimate for this missing potential outcome.

To construct our synthetic control unit we define a $(\mathrm{k} \times 1)$ vector of weights $\mathrm{W}=\left(\omega_{2}, \ldots, \omega_{k+1}\right)$ such that $\omega_{k} \geqslant 0$ for $\mathrm{k}=2, \ldots, \mathrm{K}+1$ and $\omega_{2}+\ldots+\omega_{k+1}=1$. Each $\mathrm{W}$ then represents one particular weighted average of control units and therefore one potential synthetic control unit. Abadie and Gardeazabal (2003) [1] and Abadie etal. (2010) [2]propose to chose the weights $\mathrm{w}^{*}$ such that the resulting synthetic control unit best approximates the unit exposed to the intervention with respect to the outcome predictors and the linear combinations of preintervention outcomes. Formally, we select $\mathrm{w}^{*}=\omega_{2}^{*}+\ldots+\omega_{k+1}^{*}$ such that $\sum_{k=2}^{k+1} \omega_{k}^{*} \pi_{k 1}=\pi_{1 t}, \sum_{k=2}^{k+1} \omega_{k}^{*} \pi_{k 2}=\pi_{12 l \ldots . .,} \quad \sum_{k=2}^{k+1} \omega_{k}^{*} \pi_{k T_{0}}=\pi_{1 T_{0}}$ and $\sum_{k=2}^{k+1} \omega_{k}^{*} Z_{k}=Z_{1}$ hold (or hold approximately). Then $\widehat{\alpha_{1 t}}=\pi_{1 t}-\sum_{k=2}^{k+1} \omega_{k}^{*} \pi_{k t}, \mathrm{t} \in\left[T_{0}+1, \cdots, T\right]$ yields an estimator of $\alpha_{1 t}$ in periods $\mathrm{T}_{0}+1, \mathrm{~T}_{0}+2, \ldots, \mathrm{T}$. Based on above analysis, synthetic control method fits the "counterfactual state" of a treatment group by using the control group (In other words, it hypothesized what the country who implemented the inflation targeting will be like if it didn't adopt the inflation targeting). The policy effect of inflation targeting was interpreted by a contrast analysis between the control group and the treatment group. The synthetic control method was proposed by Abadie and Gardeazabal (2003). It has been widely used in other policy evaluation fields[9][10].

\section{Empirical analysis based on the synthetic control method}

\section{(a) Sample}

Based on the above analysis, the synthetic control method needs a control group. Since the study object, Japan (the treatment group), is an industrial country, the control group shall be an industrial country too. Specifically, emerging countries (e.g. Chile, Mexico, Czech Republic and Hungary) in 34 members of OECD were eliminated and the rest 22 industrial countries were chosen as the control group.

\section{(b) Variables}

This paper focused on analyzing policy effect of inflation targeting on inflation in Japan. Therefore, the CPI rate was set as the evaluation variable. Based on existing associated studies conclusions, main influencing factors of the evaluation variable (e.g. prediction variables in the synthetic control method) were determined the actual growth rate of GDP and lagged variable of CPI rate.

\section{(c) Data sources}

The interval of samples was from 1990 to 2016. Data of above variables were collected from "EIU Country Data” database.

\section{(d) Results}

Analysis results are shown in Fig. $3^{3}$. The blue line (solid line) shows the actual changes of CPI inflation rate in Japan and the green line (dotted line) is changes of the "fitted" CPI inflation rate (under the hypothesis of no implementation of

3 The programming of the synthetic control method consulted to Abadie and Gardeazabal (2003). inflation targeting in Japan, how does the CPI inflation rate change under this "counterfactual state".) The red line is the starting point of implementing the inflation targeting in Japan.

In Fig.3, the blue line and green line overlap well in the left of the red line (before the implementation of inflation targeting), indicating that the synthetic control method fits a Japan under the "counterfactual state" well. In the right of the red line, the "fitted" CPI inflation rate is lower than the actual CPI inflation rate. This reveals that if Japan didn't implement this monetary policy in early 2013, the CPI inflation rate might be lower (In other words, inflation targeting inhibits further deterioration of deflation in Japan).

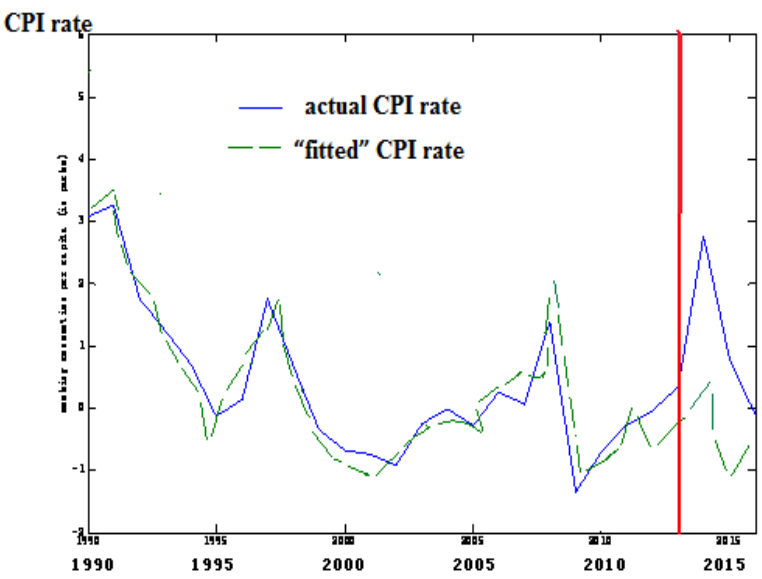

Fig. 3. CPI rate VS “fitted” CPI rate

According to above analysis results, the policy effect of inflation targeting was not satisfying since its implementation in early 2013. However, it inhibited further deterioration of deflation to some extent.

\section{SUMMARY}

After years of debates, Japan began to implement the inflation targeting in early 2013. Different from other countries who adopt the inflation targeting, Japan applied this monetary policy to get rid of the long-term dilemma of deflation. How does its policy effect? An empirical analysis on the policy effect of inflation targeting was carried out by using the synthetic control method. The results demonstrated that although inflation targeting fails to achieve satisfying outcomes, it can inhibit further deterioration of deflation to some extent.

This paper is high innovative in term of study contents since there are few literatures on the policy effect of inflation targeting in Japan.

\section{REFERENCES}

[1] Abadie, A. and Gardeazabal, J., "The Economic Costs of Conflict: A Case Study of the Basque Country”, American Economic Review, vol. 93 (1), pp.113-132, 2003.

[2] Abadie, A., Diamond, A., Hainmueller, J., "Synthetic Control Methods for Comparative Case Studies: Estimating the Effect of California's Tobacco Control Program", Journal of the American Statistical Association, vol.105, pp.493-505, 2010. 
[3] Hammon, G., "State of the art of inflation targeting”, CCBS Handbook No.29, 2012.

[4] Liu Donghua, "Can Inflation Targeting Stabilize Inflation Expectations ?”, Finance \& Trade Economics, pp.62-71, 2014(07). (In Chinese).

[5] Li Xiao and Wang Han, "The New QE of Bank of Japan: Characteristics, Background and Challenges”, International Economic Review, pp.91-110, 2017(05). (In Chinese).

[6] Roger, S., "Inflation Targeting at 20: Achievements and Challenges”, IMF Working Papers,WP/09/236, 2009.
[7] Salem, A. and Diedm, T., "Inflation Targeting: A three-decade perspective”, Journal of Policy Modeling, Vol. 34(5), pp. 621-645, 2012.

[8] Svensson, L. E.O., "Inflation Targeting”, NBER Working Paper, No.16654, 2010.

[9] Su Zhi and Hu Di, “Is Inflation Targeting Effective? New Evidence from the Synthetic Control Methods”, Economic Research Journal, pp.74-88, 2015(06). (In Chinese).

[10] Wan hui-Ki, Xie Yimeng, Hsiao Cheng, "Panel data approach vs synthetic control method”, Economics Letters, vol.164, pp.121-123, 2018. 